\title{
Adaptive method of generation of optimal production orders
}

\author{
Galina Korableva ${ }^{1, *}$ and Elena Kucherova $^{1}$ \\ ${ }^{1}$ Moscow state University of technology and management. K. G. Razumovsky (Smolensk branch), \\ Lenin street 77, Smolensk region, Vyazma, 215100, Russia
}

\begin{abstract}
The article describes the approach to the generation of production or sales orders for enterprises with ordering planning system. The adaptive method of orders' generation for production and sales of products is multi-level and includes several stages, allowing forming almost optimal package of applications from consumers, obtained by a mathematical model, the optimization criterion of which is the profit function from product sales. The functional structure of the automated decision support system, which is a tool for implementing an adaptive methodology, is considered. The developed method will reduce energy costs during transportation and storage of production orders.
\end{abstract}

\section{Introduction}

In the conditions of stiff market competition, many enterprises of the Russian Federation plan their production activities on the basis of previously received orders for their products. Ordering planning systems are common in mechanical engineering, for example, in the automotive industry, in enterprises producing sophisticated household appliances, and in the defense industry. Trade organizations, especially those that do not sell essential goods, but rather rarely purchased products such as furniture, building materials, plumbing, medical equipment, expensive computer and office equipment, and household appliances also work on the basis of orders previously received from customers. The received orders allow minimizing the risks associated with the investment of working capital in the production or purchase of products unclaimed by customers[1-3].

The basic unit of planning the volume of production or deliveries in ordering systems is an order formed on the basis of applications from potential consumers. The order structure has a significant impact on the results of the business's activities. Therefore, in modern conditions, the process of forming a production or sales order should be based on economic optimization criteria, take into account available production or financial resources, orders of potential products' consumers and be adaptable to the effects of random factors generated by the market environment.

\footnotetext{
* Corresponding author: kyzmina tk@,mail.ru
} 


\section{Materials and methods}

The planning systems of "Vyazma Machine-Building Plant" OJSC, "LG Electronics Rus" LLC, "Volkswagen Group Rus" LLC, "Avangard" JSC and a number of other industrial and trade enterprises were reviewed in the study.

The main methods of research of planning systems and the generation of production orders of enterprises are analysis, synthesis, abstraction and modeling. In developing an adaptive methodology, the theoretical principles of statistical data analysis (cluster analysis), optimal control theory, and production management theory were used.

In designing an automated system for adaptive generation of an optimal production order, the theoretical principles of the theory of adaptive systems and relational databases were applied.

For approbation of the developed methods, models, algorithms and their implementation, an automated decision support system was created. Database Management System Clarion 10, modular programming and object-oriented technology, and RAD (Rapid Application Development) application development approach were usedas an instrumentarium in the study $[4,5]$.

\section{Results}

According to the results of the analysis of the activity of the ordering systems of the production or sale of products, an adaptive method of the optimal order generation was proposed. It is implemented in the form of an automated decision support system and includes the following provisions:

1) Based on the mathematical model (1), an optimal base production or sales order is formed:

$$
f=\sum_{i=1}^{k} c_{i} x_{i} \rightarrow \max ,\left\{\begin{array}{l}
\sum_{j=1}^{k} r_{i j} x_{j} \leq z p_{i} \quad i=\overline{1, p} \\
x_{i} \in Z, \quad i=\overline{1, k} \\
x_{i} \leq d_{i}, \quad i=\overline{1, k} \\
x_{i} \geq a_{i}, \quad i=\overline{1, k} \\
\sum_{i=1}^{k} k f_{i} x_{i} \leq P M \\
\sum_{i=1}^{k} \beta_{i} x_{i} \leq \text { koefPM }
\end{array}\right.
$$

where the criterion function is the profit from the sale of products (produced or taken for sale): $f=(\overrightarrow{\boldsymbol{c}}, \overrightarrow{\boldsymbol{x}})=\sum_{i=1}^{k} c_{i} x_{i} \rightarrow \max$.

Consider the restrictions of the mathematical model, which, depending on the solution of the problem of a generation of a production or sales order, include not all restrictions.

2) Restrictions to the production volumes for all items of the basic production order, determined by the production potential of the enterprise (2):

$$
\sum_{i=1}^{k} k f_{i} x_{i} \leq P M, \text { where } 0<k f_{i}<+\infty, \quad i=\overline{1, k}
$$

$\sum_{i=1}^{l} \beta_{i} x_{i} \leq k o e f P M$, where $l \leq k, 0<\beta_{i}<+\infty, \quad i=\overline{1 . . l}, 0 \leq k o e f \leq 1$ and $\forall x_{i} \in \mathrm{G}$ is a set of products with increased labor, $\mathrm{G} \subset \mathrm{M}$.

3) Restrictions to the production volumes for all items of the basic production order, 
determined by the stocks of raw materials and inventory materials that are at the warehouse of the enterprise (3):

$$
\begin{gathered}
\sum_{j=1}^{k} r_{1 j} x_{j} \leq z p_{1} \\
\sum_{j=1}^{k} r_{2 j} x_{j} \leq z p_{2} \\
\cdots \cdots \cdots \\
\sum_{j=1}^{k} r_{(p-1) j} x_{j} \leq z p_{(p-1)} \\
\sum_{j=1}^{k} r_{p j} x_{j} \leq z p_{p} .
\end{gathered}
$$

4) Restrictions to the maximum production volumes for each item of the optimal basic production order, determined by the orders of consumers:

$$
x_{1} \leq d_{1}, x_{2} \leq d_{2}, \ldots, x_{k} \leq d_{k},
$$

Where $d_{i}$ is the total number of products $t_{i}$, the order for which is in the orders of consumers.

5) Restrictions to the minimum production volumes for each item of the optimal basic production order, determined by the urgent orders or statistical data on the demand for specific types of products:

$$
x_{1} \geq a_{1}, \quad x_{2} \geq a_{2}, \ldots \ldots \ldots, \quad x_{k} \geq a_{k} .
$$

If an enterprise has no fixed-term contracts and statistical data on sales volumes during the model building period, then $\forall i: \quad a_{i}=0, \quad i=\overline{1, k}$.

6) Due to the fact that the products of engineering enterprises, household appliances, automotive industry products, etc. is expressed in units, then all variables (coordinates of the vector of the optimal production order) should take only integer values: $x_{1}, x_{2}, x_{3}, \ldots .$. , $x_{k} \in Z$.

7) In the mathematical model related to large-scale problems, the number of restrictions is reduced due to the use of cluster analysis of the products components of the production order. Its results are used to determine groups of elements with common technological properties. To reduce the number of inequalities of restrictions within the cluster groups, an algorithm for allocating priority restrictions is used to assign component safety factors and calculate inventory levels.

The method of feature groups development in the clustering algorithm of the components of multitopic products of engineering industries has been developed. Thirtyfive signs that determine technological properties of a product components, their ability to have technological substitutes, and applicability in the production of products of a certain model were identified in the applied implementation of this method.

8) Calculation of the basic optimal production order is carried out on the basis of the economic and mathematical model (1) using the decomposition technique implemented using the discrete search algorithm. The main idea of the algorithm is to divide the original problem of discrete programming of large dimension into subproblems with their subsequent solution. On the basis of the experiments carried out to find a solution of the economic and mathematical model on a PC, it was established that the subproblems of four dimension are the optimal ones [6-8].

The discrete search algorithm consists of two stages. At the first stage, in order to accelerate the convergence of the method, the initial problem of high dimensionality is divided into subproblems as follows. First, the sequence of $\vec{d}$ vector coordinate values is ordered in descending order $\left(d_{i}, i=\overline{1, k}\right.$ determines the maximum volume by the $i^{\text {th }}$ nomenclature position, due to the number of orders at the enterprise). 
Then, from the variables of the $\vec{x}$ vector of the basic production order, groups are formed in accordance with their order in $\vec{d}$, containing four variables each (excluding the latter, which contains $k-\left(K \_Z-1\right) 4$ variables). The initial problem of discrete programming is divided into subproblems corresponding to the formed groups of variables. The total number of subproblems is determined by the formula (4):

$$
K \_Z=k \operatorname{div} 4,
$$

where div is an integer division.

The basic optimal production order can be represented as $\vec{x}=\sum_{i=1}^{K-Z} \overrightarrow{x^{(i 1)}}$. The vector of profit from the sale of a production unit included in the production order is representedas $\vec{c}=\sum_{i=1}^{K} Z \overrightarrow{c^{(i 1)}}$.

The criterion functions of the subproblems are determined as $f^{(i 1)}=\left(\overrightarrow{c^{(i 1)}}, \overrightarrow{x^{(i 1)}}\right)=\sum_{i=1}^{k^{(i 1)}} c_{i}^{(i 1)} x_{i}^{(i 1)}$ (the criterion function of the subproblems with the number $i 1, i 1=\overline{1, K_{-} Z}$ ). The inequality of constraints is divided similarly to the vector of variables.

At the second stage of the discrete search algorithm, integer points in the region of feasible solutions are determined for each subproblem. The values of the criterion function at these points are calculated. Points or a point $\overrightarrow{x^{(i 1) *}}, \quad i 1=\overline{1, K_{-} Z}$ of space of $k^{(i 1)}$ dimension are selected. This point should guarantee the maximum values of the criterion function of the subproblem $f^{(i 1)}\left(\overrightarrow{x^{(i 1)^{*}}}\right)$. The optimal solution to the original problem of discrete programming is determined as $\vec{x}=\sum_{i=1}^{K} Z \overrightarrow{x^{(i 1)} *}$, which is the optimal basic production order. The optimal value of the criterion function is $f=\sum_{i=1}^{K} Z f^{(i 1)}\left(\overrightarrow{x^{(i 1)} *}\right)$.

9) Generation of a production or trade order actually carried out by an enterprise. For this purpose, an algorithm to optimize the structure of the initial package of orders has been developed. The idea of this algorithm is to develop all possible groups of contracts (from one, two, etc.) that have $\vec{\mu} \geq \overrightarrow{0}$, where $\mu_{i}=x_{i} *-\sum_{j=1}^{n} x_{i}{ }^{(j)} \geq 0, i=\overline{1, k}, k$ is the number of product models in the optimal production order; $x_{i}{ }^{*}$ is the number of products of the $i^{\text {th }}$ model in the basic production order; $x_{i}$ is the number of products of the $i^{\text {th }}$ model in the developed group of contracts. From the developed groups of contracts, the one is chosen for which $\mu_{g}=m\left(\sum_{i=1}^{k}\left(x *_{i}-\sum_{j=1}^{n}\right.\right.$ dog $\left.\left.x_{i}^{(j)}\right)\right)=\sum_{i=1}^{k} m\left(x_{i}^{*}\right)-\sum_{i=1}^{k} \sum_{j=1}^{n} \sum^{\operatorname{dog}} m\left(x_{i}^{(j)}\right) \rightarrow$ min, where the function $m$ is the profit function from the products sale. A set of products of different models in the selected group of contracts will be a realizable production order.

10) Adjustment of the formed order executed by the enterprise in accordance with the changed conditions for its implementation. The third and subsequent stages of adaptive generation of a production order in accordance with the adaptive method are initiated when 
changes occur in the state of resources or production capacities, at an early stage of implementation of the realized production order. All actions of these stages are carried out in accordance with the algorithm of adaptation of the executed production order to the changed conditions of its implementation. At the initial stage of the algorithm, it is necessary to determine the product models with the quantities produced during the period when the enterprise executed the production order to be adjusted, and to indicate the situations (noted above) that affected the process of its successful implementation.

If some orders are refused, then an enterprise makes a list of contracts, which are no longer required to be executed. After this, a check is made: whether the listed contracts are included in the executable production order. If not, then orders are excluded from the database of the automated system implementing the described method. If any stopped contracts were included in the adjustable production order, then on the basis of these contracts a vector $\overrightarrow{x_{s t}}$ is formed. In this case there is a need to select a new package of orders (instead of stopped ones) for this vector.

The automated system, using the algorithm for optimizing the structure of the orders package from contracts with the "entered" status, forms a group similar to the package of contracts to be excluded in the form $\mu_{g}=m\left(\sum_{i=1}^{k}\left(x_{i s t}-\sum_{j=1}^{n_{d o g}} x_{i}^{(j)}\right)\right)=\sum_{i=1}^{k} m\left(x_{i s t}\right)-$ $\sum_{i=1}^{k} \sum_{j=1}^{n \_\operatorname{dog} 1} m\left(x_{i}^{(j)}\right)$. Contracts from the newly formed regeneration group are assigned the "implemented" status, which means their inclusion in the production order of the current period. Stopped contracts are excluded from the database of the automated system.

If the production capacity of the enterprise has changed, then the relevant information is entered in the directory of production capacity. If during the period of implementation of the adjusted production order, the company managed to produce a non-zero number of products, then, taking into account this fact, the constraints of the economic and mathematical model (1) are recalculated.

In this case we get the optimal base production order $\vec{x} * *$, corresponding to the changed parameters of the production system. After these stages, a new package of orders is selected from the package of contracts defining the adjustable production order using the algorithm for optimizing the structure of the contracts' package, approximating calculated

$$
\overrightarrow{x * * \mathrm{by}} \mu_{g}=m\left(\sum_{i=1}^{k}\left(x * *_{i}-\sum_{j=1}^{n_{-} \operatorname{dog} 2} x_{i}^{(j)}\right)\right)=\sum_{i=1}^{k} m\left(x * *_{i}\right)-\sum_{i=1}^{k} \sum_{j=1}^{n} m\left(x_{i}^{(j)}\right) \text {. }
$$

Then it is formed a package of orders, which cannot be fulfilled in the current planning period due to decreased production capacity. For this, the status of contracts that are not included in the group of orders approximating $\overrightarrow{x * *}$ is changed to "fulfillment is suspended". The fact of their exclusion from the plan of the current period is brought to the attention of customers. If the customer decides not to withdraw the contract, but wait for its fullfillment, the status of such contracts in the database of the automated system is changed to "received". If a potential consumer decides to refuse to purchase products, then such orders are excluded from the database.

In terms of stochastic changes in the stock of material resources, it is necessary to enter their new values. Then an analysis of the volumes of products produced in accordance with the production order being adjusted is carried out, as well as the economic and mathematical model (1) is calculated. In the following stages, the actions of the automated system are similar to those described for the situation that characterizes the decrease in production capacity of the enterprise. 
If during the operation of the enterprise there are situations described above, then first, a reduction in production capacity or the value of production resources is taken into account, and then the withdrawn orders are processed.

An automated decision support system has been developed for implementing an adaptive method for generation of a production order on a PC. This system includes the following functional blocks:

- a block of the automated system settings;

- a block of input and processing of received orders;

- a block of the cluster analysis of a set of initial components of products;

- a block for calculation the parameters and values of the criterion function (profit);

- a block for evaluation the parameters and solving a basic optimization model;

- a block of generation of the optimal fulfilled production order of the enterprise;

- a block of fulfilled production order adjustment;

- a block of the initial orders adjustment, taking into account the order of production.

\section{Conclusions}

Conducted research, theoretical results, developed algorithms, techniques and software of the automated system are aimed at solving the problem of generation of the optimal production order in the stochastic market processes, in the variability of the model series of products of engineering production, which is of very importance.

The developed adaptive methodology for the generation of production and trade orders, as well as the automated decision support system implementing it, are tested at "Vyazma Machine-Building Plant" OJSC. They can be applied at enterprises operating on the basis of an ordering planning system.

\section{References}

1. S.V. Nazarov, Architecture and design of software systems (Moscow, 2017)

2. E.B. Zolotukhina, S.A. Krasnikova, A.S. Vishnya, Modeling of business processes (Moscow, 2017)

3. G.N. Kalyanov, CASE-technologies. Consulting in automation of business processes (Moscow, 2002)

4. B. Marchi, S. Zanoni, M. Pasetti, L. E. Zavanella, I. Ferretti, Industrial Systems Engineering (to be published)

5. S. Zanoni, B. Marchi, M. Pasetti, L. Zavanella, 2018 Industrial Efficiency Conference, Berlin (2018)

6. R. Golov, T. Narezhnaya, N. Voytolovskiy, V. Mylnik, E. Zubeeva, MATEC Web of Conferences (2018) https://doi.org/10.1051/matecconf/201819305080

7. I. Lukmanova, R. Golov, E3S Web of Conferences (2018) https://doi.org/10.1051/e3sconf/20183302047

8. A.V. Lyushinskiy, E.S. Fedorova, N.R. Roshan, E.M. Chistov, R.S. Golov, https://doi.org/10.1080/09507116.2017.1318505 (2017)

9. G.G. Artyushina, O.A. Sheypak, R.S. Golov, ACM International Conference Proceeding Series (2017) https://doi.org/10.1145/3026480.3029590 